\title{
CONFLITOS E TENSÕES NA PRODUÇÃO DA INCLUSÃO ESCOLAR DE CRIANÇAS POBRES, NEGRAS E MESTIC̣AS, BRASIL, SÉCULO XIX
}

\author{
Cynthia Greive Veiga*
}

RESUMO: O objetivo central deste texto é discutir o processo de inclusão das crianças pobres, negras e mestiças na escola elementar a partir da prerrogativa constitucional de extensão da escolarização a todos os cidadãos brasileiros, com ênfase nos estudos sobre a província de Minas Gerais. Com base em larga investigação documental (relatos de governo, legislação, ofícios e correspondências diversas, mapas estatísticos de população, registros de frequência escolar) e bibliográfica (Norbert Elias, Georges Rudé, Bronislaw Geremek, Georges Duby, Maria Beatriz Nizza da Silva), foi possível analisar as tensões e os conflitos para a efetivação da obrigatoriedade escolar, devido às condições materiais e especificidades culturais da população. Tais conflitos manifestaram-se de distintas maneiras, indicando embates entre famílias, professores e gestores do ensino. A hipótese levantada é a de que a precariedade do desenvolvimento da escola pública no Brasil, ao longo do século XIX, esteve associada à também precária condição de vida da população. Esse fato interferiu no entendimento quanto às possibilidades de escolarização das crianças pobres, negras e mestiças e quanto à qualidade de sua inserção social.

Palavras-chaves: Escolarização; Crianças; Século XIX.

\section{CONFLICTS AND TENSIONS IN THE PRODUCTION OF SCHOOL INCLUSION OF POOR, BLACK AND HALF-CASTE CHILDREN, BRAZIL, 19TH CENTURY}

ABSTRACT: The main aim of this paper is to discuss the inclusion process of poor children in elementary school based on the constitutional right of access to schooling to all Brazilian citizens, with emphasis on the Minas Gerais State. Through extensive documental (government reports, laws, assorted official correspondence, maps of population statistics, class attendance) and bibliographical (Norbert Elias, Georges Rudé, Bronislaw Geremek, Georges Duby, Maria Beatriz Nizza da Silva) research, it was possible to identify tensions and conflicts in the implementation of compulsory schooling as a result of material conditions and the cultural specificities of the population. Such conflicts were expressed in various ways and indicated a struggle among families, teachers and public authorities. The hypothesis developed is that the rather precarious establishment of public schools in Brazil, during the 19th century, was associated with the population precarious conditions of life, which interfered with the understanding of the feasibility of schooling for poor children and the quality of their social participation.

Keywords: Schooling, Poor children, 19th Century.

\footnotetext{
* Doutora em História pela Universidade Estadual de Campinas (UNICAMP); Professora da Faculdade de Educação da Universidade Federal de Minas Gerais (UFMG). E-mail: greive@fae.ufmg.br
} 
O texto que ora se apresenta é componente de uma pesquisa concluída ${ }^{1}$ referente ao período imperial brasileiro (1822-1889) e teve como objeto mais geral interrogar sobre as crianças que tiveram acesso e/ou frequentaram as aulas de instrução elementar pública, no Brasil, século XIX, com recorte para a Província de Minas Gerais. A partir de ampla pesquisa de fontes documentais, tais como: legislação; relatórios de presidentes de província, de delegados literários e inspetores; ofícios e correspondências diversas; mapas de populações; mapas de frequência de alunos e mapas das cadeiras de instrução elementar, foi possível refletir sobre as estratégias de instituição da escola como lugar de produzir a infância civilizada.

Algumas considerações são aqui inicialmente necessárias no âmbito das definições. De acordo com Kuhlmann Jr. e Fernandes (2004, p. 15), a história da infância possui como campo de investigação a "his-tória da relação da sociedade, da cultura, dos adultos com essa classe de idade". Nesse sentido, discutir a produção da infância em sua dinâmica relacional com o mundo adulto demanda a problematização dos diferentes processos que interferiram na definição e na consolidação desse tempo geracional como distinto do mundo adulto, aqui, em particular, o lugar da escolarização no século XIX como favorecimento da distinção geracional (VEIGA, 2004). Considerando-se ainda as reflexões de Kuhlmann Jr. (1998) e Kuhlmann Jr. e Fernandes (2004), compreende-se também a infância como uma condição da criança, havendo múltiplas possibilidades de vivência da infância. Temos ainda que, nesse campo em específico, está sendo tomada a perspectiva das representações da infância elaborada pelo mundo adulto, numa circularidade de relatos produzidos por adultos distintos.

A produção da infância nas operações escriturísticas da administração da instrução elementar no século XIX, interpelada no âmbito das problematizações da pesquisa, possibilitou a percepção da existência de conflitos vários no processo de institucionalização da obrigatoriedade escolar na província de Minas Gerais, ocorrido a partir do estabelecimento da lei n.13 de 1835. Nas estratégias discursivas das elites políticas e intelectuais, a obrigatoriedade da frequência à instrução elementar, seja pública seja particular ou em domicílio, apresenta-se como imperativo necessário à produção de uma sociedade civilizada. E uma sociedade civilizada se constrói a partir da escolarização da infância, numa característica peculiar do tempo, a produção da criança civilizada. 
É nesse sentido que se faz referência aqui a práticas de inclusão, entretanto o termo não está sendo tomado a partir da conotação atualmente em circulação. Não se trata de um anacronismo, mas da problematização histórica de um tempo em que ocorreram diferentes processos de produção da inclusão social, dado o contexto de formação do Estadonação, ou seja, dos processos de constituição das instituições públicas encarregadas de prover a nação e dotá-la de uma população nacional, portanto de cidadãos, enquanto ações necessárias de governo. O que se pretende problematizar então são as práticas político-culturais de inclusão, tomando a obrigatoriedade escolar como uma das estratégias de inclusão de todas as crianças livres ao projeto civilizador, portanto sua homogeneização cultural como componente da estruturação da monarquia constitucional brasileira.

Como parte integrante do processo de formação do Estadonação brasileiro durante o período imperial, elaborou-se o imaginário de uma sociedade disforme a ser formatada pelas instituições. Esse imaginário tanto possibilitou a autorrepresentação das elites como pedagogas da nação, quanto das populações como portadoras de anomias várias. $\mathrm{Na}$ análise de Norbert Elias (2000), essa dupla representação indica uma situação de equilíbrio instável de poder. Também Baczko (1985), em suas reflexões relativas à imaginação social, afirma que, no processo de produção dos imaginários em situações de conflito, ocorre a produção da imagem desvalorizada do outro no sentido de invalidar sua legitimidade e engrandecer o poder daqueles que querem conquistar legitimidade por meio de adesões.

As tensões presentes no processo de institucionalização da escolarização podem ser pensadas num quadro de embate de representações no qual esteve presente um imaginário perpassado pelas tensões entre uma infância e uma população rudes e uma infância e uma população civilizadas. Podemos afirmar que o contexto de proliferação dos ideais escolarizadores na sociedade apresentou-se como momento altamente profícuo de elaboração do imaginário de sociedade disforme e da autorrepresentação positiva das elites. Segundo Baczko (1985, p. 311), "O imaginário social torna-se inteligível e comunicável através da produção de discursos nos quais e pelos quais se efetiva a reunião das representações coletivas numa linguagem”. Essa questão é, pois, fundamental para apreender o sentido de se transformar a infância rude em civilizada. 


\section{Condições de produção de adesão a uma sociedade civilizada}

Minas Gerais se localiza no Sudeste brasileiro e, diferentemente das primeiras localidades colonizadas, não possui contato com o mar, sendo que, na época de sua ocupação, o acesso era dificultado pelas matas fechadas e pelas regiões montanhosas. A então capitania ${ }^{2}$ estabelecida em 2 de dezembro de 1720 já havia sido visitada desde meados do século XVI por expedições de homens à procura de ouro, somente encontrado nas últimas décadas do Seiscentos. Até então o território era subordinado administrativamente ao Rio de Janeiro e, a partir da Carta Régia de 9/11/1709, foi criada a Capitania de São Paulo e das Minas do Ouro. Com o movimento denominado "Sedição de Vila Rica", foi então criada a nova Capitania, tendo ocorrido algumas disputas de fronteira até 1816.

A descoberta de ouro nas Minas Gerais produziu significativo deslocamento de populações tanto de origem interna quanto provenientes do norte de Portugal, sendo motivo de preocupações por parte das autoridades. De acordo com Botelho (2003),

Acampamentos surgiam rapidamente nas vizinhanças dos rios e ribeirões e nas encostas das montanhas, onde era encontrado o metal; nessas aglomerações, grassavam a fome, a desordem e as disputas pelas posses das datas. Quando chegavam notícias de achados promissores, os moradores freqüentemente abandonavam os povoados e deslocavam para outras regiões, onde iriam erguer as mesmas moradas toscas. (BOTELHO; ROMEIRO, 2003, p. 237)

No início do Setecentos, ocorreram medidas restritivas em relação à entrada no território, bem como o estabelecimento da burocracia administrativa local por meio da fundação de vilas, comarcas, câmara, senado e consolidação da Igreja Católica. A fixação dos moradores e o desenvolvimento dos núcleos urbanos, especialmente nas áreas mineradoras, produziram condições para o controle populacional, destacandose que, em fins do século XVIII, a Capitania de Minas Gerais era a mais populosa da América portuguesa.

É nesse sentido que se costuma falar que Minas primeiro foi urbana para depois se ruralizar, se tomarmos naquela qualificação as questões inerentes ao espaço urbano, no que se relaciona ao crescimento demográfico, aos aparatos administrativos, às edificações, às estruturas de 
comércio, à circulação monetária, mas, principalmente, às tensões entre ordem e conflitos sociais. Associado ao crescimento urbano ocorreu o desenvolvimento de atividades paralelas, como agricultura, pecuária e manufaturas de pano. Isso explica a permanência do destaque econômico de Minas Gerais, mesmo passado o auge minerador (1735-1759), bem como a diversidade étnica e social da população.

Diferentes historiadores ${ }^{4}$ têm investigado a dinâmica da economia mineira em fins do século XVIII e início do século XIX, contrariando as teses de estagnação devido à diminuição das atividades mineradoras. Tal dinâmica econômica e financeira fez-se com base na agropecuária, na indústria têxtil, em manufaturas de ferro, em empreendimentos de mineração e no comércio de escravos, possibilitando a consolidação de uma elite econômica e política. Ao mesmo tempo, ocorreu a proliferação de uma população pobre, composta de escravos e trabalhadores livres, sendo significativa a presença da mão de obra feminina e infantil (LIBBY,1987).

Destaca-se também que Minas Gerais possuía o maior plantel escravista do império (LIBBY, 1988), entretanto não era superior à população livre, congregando em torno de um terço da população total. Liana Reis (1996, p. 227) observa que o aumento dos municípios e o crescimento da população urbana "composta de escravos, negros e mulatos forros e homens livres" trouxeram problemas para as autoridades provinciais no tocante à manutenção da ordem. Também Regina Duarte (1995) enfatiza a preocupação das autoridades com os vadios e a criação de várias leis de repressão à vadiagem. Por outro lado, crescia o número de trabalhadores livres que se empregavam nas minas e indústrias de tecelagem. Evidentemente que tais aspectos carregavam as tintas das escritas dos gestores políticos a favor da difusão da instrução como fator de disciplina. Os relatores de uma comissão para discutir a situação da instrução de Minas Gerais em 1865 afirmavam que "A educação popular é ainda um elemento da ordem, o mais forte obstáculo do crime, o mais eficaz meio preventivo da desordem e da anarquia". ${ }^{5}$

O trabalho de Souza (1982) nos despertou para refletir sobre as condições da população mineira em fins do século XVIII, quando os "desclassificados do ouro" alimentavam a repressão à vadiagem. Para o século XIX, foi possível encontrar vários indicadores de permanência de tal situação. 
Perguntarmos sobre as condições de adesão a um projeto de sociedade civilizada implica minimamente conhecer as representações que se fizeram da população a ser civilizada. A principal fundamentação para essa discussão está nas proposições conceituais de Elias (1993; 1994) relativas à civilização como processo de longa duração histórica, que teve sua culminância no século XIX, no contexto em que algumas sociedades se autorrepresentaram como civilizadas.

Para a discussão da sociedade brasileira do século XIX é importante atentarmos para a impossibilidade de transportar um conceito, civilização, que teve um processo de construção histórica tão demarcada no contexto europeu. Entretanto, isso não significou, evidentemente, que o termo não tenha sido incorporado pelas elites brasileiras, ressalvandose a peculiaridade dessa apropriação na medida em que o utilizavam para se autorreferirem, e não para se referir a uma nação, como forma de produção de sua autoimagem e, por vezes, isso punha em dúvida as condições do restante da população de vir a ser civilizada. Nos relatos dos presidentes de província é recorrente o discurso em relação à existência de uma população desqualificada, atrasada, caracterizando o discurso a favor da disseminação da instrução.

Outro aspecto fundamental sobre a população mineira é o alto grau de mestiçagem. Martins (1990), em análises relativas aos mapas de população dos anos 1833-1835, registra 29,2\% de brancos, 34,4\% de pardos e $36,4 \%$ de pretos. Esses dados são confirmados em relatos de viajantes, como, por exemplo, Halfeld e Tschudi (1998, p. 106), em publicação de 1862 sobre a província: "Uma grande parte da população desta província compõem-se de negros livres, mestiços de negros com brancos e de brancos e negros com índios, envolvendo todos os tipos de mestiçagem dessas três raças entre si".

Em relação aos dados sobre a condição jurídica, temos os seguintes valores aproximados sobre a população escrava: 1821, 35\%; 1833-35, 33\%; 1855, 25\%; e 1873, 18,2\%. ${ }^{6}$ Podemos afirmar, portanto, que a população mineira foi caracterizada pela presença de número significativo de pardos e negros livres, em detrimento de brancos livres. Esse dado é significativo para problematizarmos a peculiaridade que o sentido de civilizar possuiu em uma sociedade mestiça, representada nos registros oficiais como sinônimo de população selvagem e bárbara. Destaca-se que essa representação se fez não somente pela herança 
escravista presente na cor da população não-branca. Para além desse aspecto, é possível discutir que desde o processo de colonização o estranhamento que se estabeleceu entre as distintas práticas culturais de portugueses, africanos e indígenas foi marcado pela autopercepção dos primeiros como portadores das civilidades, atribuindo aos outros os estigmas de anômicos. Tal representação esteve expressa num conjunto de atribuições como a linguagem, as diferentes manifestações culturais (música, danças, celebrações, ritos) e, portanto, nos comportamentos, sendo que a cor da pele se apresentou como componente dessas atribuições (ELIAS, 2000).

Quero afirmar que a produção dos mestiços e negros como grupo inferior na sociedade brasileira se fez como um "ato de evitação" de um conjunto de referências étnicas, nas quais as marcas raciais e a herança escravista são componentes, e não definidores a priori de sua inferiorização. Observa-se ainda que o próprio conceito de preconceito racial é limitador da compreensão das formas de estigmatização (ELIAS, 2000). Os "atos de evitação" não se estabeleceram por diferenças físicas isoladamente, mas pelas formas como se deram as vinculações entre os distintos grupos étnicos como manifestação das relações de poder.

Portanto, as condições de produção de adesão a uma sociedade civilizada foram perpassadas por conteúdo étnico altamente significativo. A ênfase na necessidade de produção de homogeneização cultural significou a desqualificação das práticas culturais da população à qual se destinava a instrução pública elementar: a população infantil negra, mestiça e pobre. Entretanto, alguns estudiosos do período vêm afirmando que, no Brasil imperial, os negros eram proibidos de frequentar a escola. Isso se deve a uma incorreção grave, ou seja, a tradição de se tomar os negros exclusivamente na condição de escravos.

\section{Negros, todos escravos?}

O longo processo de produção dos afrodescendentes como grupo inferior na sociedade brasileira se fez por meio de práticas várias, entre elas o registro escrito, como domínio do grupo que se autodenominou portador das civilidades. Se tomarmos alguns grupamentos de registros, observaremos que foi recorrente o uso da sinonímia negros e 
escravos, produzindo uma série de equívocos na historiografia da educação brasileira por incorporar tal registro e não se dar conta da diferença entre a cor e a condição jurídica para se discutir o processo de produção da inclusão de crianças na recém-fundada nação.

Os dados da população mineira, como vimos, indicam a predominância de negros e mestiços livres sobre a população branca livre. Nesse caso, a sinonímia entre negro e escravo impossibilitaria discutir a presença de crianças negras e mestiças na escola, referendando a afirmação tão recorrente de que os negros eram proibidos de frequentar a escola, quando a proibição legal quanto à instrução pública se fazia aos escravos.

Minha pesquisa demonstrou outra dinâmica no processo de produção da escolarização, ou seja, a difusão da instrução pública elementar se fez em direção a um público muito específico, exatamente direcionado aos filhos de uma sociedade mestiça e selvagem que, por ser portadora dessas características, precisaria ser escolarizada. A partir das evidências documentais foi possível problematizar outros espaços de socialização das crianças negras e mestiças que não aqueles constituídos no reduto da escravidão.

A tradição da historiografia de reproduzir o registro onde está presente uma identidade entre escravos e negros vem de longa data. Embora haja poucos estudos relativos a escravos brancos, sabe-se que tal fato ocorreu, como nos demonstra Gutiérrez (1988), em relação ao Paraná, mesmo que pelas evidências essa prática tenha sido bastante restrita. No caso da escravidão dos grupos indígenas, também esta se deu em bem menor proporção que a dos africanos, além de ter tido caracterização diferenciada por conta da intermediação dos jesuítas. Assim, os africanos constituíram o grupo preponderante de pessoas escravizadas, cuja regulação com o tráfico se fez a partir de uma lógica mercantil específica.

Entretanto, isso não é suficiente para refletir sobre a tradição na associação entre negros e escravos. Podemos identificar outros fatores: o primeiro esteve associado à tradição historiográfica de abordagem marxista, cuja ênfase caracterizou-se pela análise das relações de trabalho sem a problematização das relações interétnicas. Outro fator é analisado por Lara (1989) como sendo a influência das ideias racistas de fins do século XIX na justificativa da escravidão, com base no argumento da raça 
negra como raça inferior. Sem dúvida, a influência das teorias raciais nos registros documentais é abundante para o final do século XIX e, particularmente, o período republicano. Entretanto, há que se destacar que os relatos de viajantes, desde o início do século XIX e tomados como fonte documental por diferentes pesquisadores, já traziam forte conotação racial.

Leite (1996) afirma que tais relatos foram referência para estudiosos como Nina Rodrigues ${ }^{8}$, Gilberto Freyre, Roger Bastide, Florestan Fernandes, Fernando Henrique Cardoso, Otávio Ianni, entre outros. Destaca-se que a apropriação foi diferenciada, seja para confirmar a inferiorização dos negros (Nina Rodrigues), seja para afirmar a democracia racial (Gilberto Freyre) ou para denunciar o racismo (Bastide, Fernandes, Cardoso, Ianni). Por sua vez, a elaboração de novas abordagens na historiografia da escravidão a partir dos 80 do século XX possibilitou, em parte, o redimensionamento da análise do processo escravista brasileiro, embora isso não tenha significado uma nova abordagem para a história dos afrodescendentes, na perspectiva de relações interétnicas ou mesmo de superação do reducionismo da história dos negros à história da escravidão. Apesar de Mattos (1997) observar que são raros os registros de convivência interétnica fora da clássica relação senhor/escravo, é preciso refletir que também, tradicionalmente, não foram produzidas problematizações sobre essa temática de maneira a possibilitar outra exploração das fontes documentais.

Mattos (1995) ressalta ainda a pouca presença do quesito cor nos registros criminais a partir da segunda metade do século XIX, problematizando esse silêncio. Diria que em uma sociedade mestiça, como, por exemplo, a província mineira, o controle populacional se referiu mais à caracterização da população em sua condição jurídica do que na composição étnica. Do ponto de vista das políticas públicas, a cor não se apresentou como problema, mas a identificação jurídica das pessoas, se livre ou escrava. Nesse aspecto, corroboro afirmações da autora a respeito do sentido comercial como característica prioritária das relações escravistas no Império, fundadas no direito positivo de propriedade, estabelecendo a condição do escravo como mercadoria. Assim, a autora afirma: 
Tal solução implicou, contraditoriamente, um amplo reconhecimento jurídico dos direitos civis de todos os cidadãos. Em outras palavras, ao contrário da maioria das regiões escravistas da América o Império dispensou o discurso "científico" de seu tempo sobre as diferenças raciais para embasar a legitimidade da escravidão, não impondo qualquer restrição legal aos descendentes de africanos já nascidos livres. (MATTOS, 1997, p. 341)

Isso evidentemente implica uma reorientação de nossas indagações quanto aos conflitos interétnicos e as manifestações de "evitação social" presentes no século XIX, no âmbito de outras relações que não as instituídas pelos mecanismos legais.

Destaco ainda que, do ponto de vista étnico, a perspectiva liberal de igualdade perante a lei, presente na constituição de 1824, não fez restrições quanto à condição étnica das pessoas, tendo sido definidos como cidadãos brasileiros

os nascidos no Brasil, quer sejam ingênuos ou libertos, ainda que o pai seja estrangeiro; os filhos de pai brasileiro e os ilegítimos de mãe brasileira nascidos em país estrangeiro que vieram se estabelecer no império; todos os nascidos em Portugal; os estrangeiros naturalizados. ${ }^{9}$

Evidentemente, temos que é necessária a melhor precisão da historiografia brasileira na definição do objeto, se história da escravidão e/ou das relações interétnicas.

\section{A obrigatoriedade escolar e as práticas político-culturais de inclusão social dos filhos dos bárbaros na sociedade civilizada}

A instrução é a fonte da moral, e sem esta nenhuma sociedade regular é possível... Logo alguma medida é precisa, e como a instrução é a primeira necessidade de um povo, o remédio é aplica-lo ${ }^{10}$

A organização da nação brasileira foi fortemente marcada por uma estratégia discursiva em que esteve presente um "nós", autorreferência da elite civilizada, e um "eles", referente àqueles que deveriam ser incluídos no imaginário da nação a se tornar civilizada. Nessa dicotomização, esteve implicada a produção de novas relações de poder, cuja característica foi a criação de estruturas institucionais necessárias para 
o controle da população e o estabelecimento de condições de governamentalidade (FOUCAULT, 1984).

O entendimento do "outro" como objeto de civilização foi enfaticamente elaborado, tendo em vista as relações interétnicas. O conhecido político José Bonifácio (1763-1838) registra, em 1813, as seguintes palavras sobre os problemas populacionais brasileiros, ainda antes da independência: "amalgamação muito difícil será a liga de tanto metal heterogêneo, como brancos, mulatos, pretos livres e escravos, índios, etc... em um corpo sólido e político" ${ }^{11}$ Em 1865, temos o seguinte registro em relatório de presidente: "É preciso criar e promover entre nós o movimento industrial: só assim terá o povo essa iniciativa individual, de cuja falta tanto nos queixamos, e que por vezes se tem atribuído a defeito inerente a raça latina". ${ }^{2}$

A escolarização do povo se apresentou, pois, como estratégia de governamentalidade e a institucionalização das aulas/cadeiras de instrução pública elementar não tiveram como alvo os filhos da elite branca. Em relatório de 1862, o vice-presidente da província relembra a intenção da difusão da instrução prescrita em lei, “... seu começo foi augurado pelas mais felizes idéias e pelos resultados que desde logo estabelecerão sensível diferença entre a nossa mais desfavorecida classe, e as de outras Províncias do império..."13. A normalização da instrução elementar pode ser problematizada em duas referências principais. A Constituição de 1824, no artigo 179, instituiu a instrução primária gratuita a todos os cidadãos como uma das garantias de "inviolabilidade dos direitos civis e políticos dos cidadãos brasileiros”, estando, portanto excluídos os escravos ${ }^{14}$.

No caso do Rio de Janeiro, o inglês Robert Walsh relata, em 1828, sobre o funcionamento das escolas lancasterianas mantidas pelo governo, que eram frequentadas por pessoas respeitáveis e que "pertenciam a todas as raças"... A educação era inteiramente gratuita, e todos eram aceitos indiscriminadamente, com exceção dos pobres escravos"15.

Outras referências são a lei provincial n. 13 e o regulamento n. 3 de 1835, que normalizaram, para Minas Gerais, a obrigatoriedade dos pais ou responsáveis de dar a instrução elementar (seja pública, particular ou em domicílio) para as crianças livres sob sua responsabilidade, não havendo qualquer restrição à cor dessas crianças. Observa-se que, para o 
cumprimento da constituição, o conjunto da legislação mineira no período imperial reitera a proibição dos escravos de frequentar as aulas públicas, ainda mesmo na legislação de 1878, sete anos após a Lei do Ventre Livre.

Ressalto que, na documentação analisada, não foi encontrado nenhum impedimento para que crianças escravas frequentassem aulas particulares ou domésticas. Em sendo propriedade particular, cabe ao senhor definir e/ou possibilitar tal acesso. Foi possível encontrar evidências de acesso de escravos a aulas particulares na documentação anterior a 1835, como os arrolados dos mapas de frequência de mestres. Em uma relação de alunos de Cachoeiro do Campo datada de 12/4/1830, registra-se que um aluno de 7 anos, Antônio, é escravo de Francisco de Paula ${ }^{16}$. Em outra listagem da mesma cidade, de 1832, da aula do professor José Carlos Ferreira, também frequentam Vitor Máximo, 5 anos, escravo de Manoel Murta, e Antônio Manuel Guerra, 7 anos, escravo de Manoel Guerra $^{17}$. Também no período posterior a 1835 encontramos o seguinte registro de 22/2/1852, do vice-presidente da província, Antônio Bhering: "em todas as fazendas há mestres particulares da família. Os próprios escravos têm seus mestres. Não é raro encontrar-se nas tabernas das estradas, nas lojas de sapateiros e alfaiates 2, 3, 4, e mais meninos aprendendo a ler"'18.

Por outro lado, na documentação, foi possível concluir que as famílias mais abastadas, em geral, não enviavam seus filhos aos mestres públicos, preferindo a aprendizagem no domicílio ou em aulas particulares. Em relatório de 1851, o vice-diretor geral da instrução assim afirma,

o número das aulas particulares é considerável. Sua freqüência é pelo menos igual a das escolas públicas. Os pais dão preferência ao ensino particular, por que nem todos os professores, ou melhor, grande número de professores, não dá as preciosas garantias de saber, honradez e moralidade, requisitos que os pais ou educandos consultam quando tratam da educação de seus filhos. ${ }^{19}$

Outro dado pode ser observado no relatório apresentado pelo inspetor geral da instrução em 1876. Leônidas Sena afirma que, na província, havia uma população de 1.440 .000 e 205.714 crianças em condições de frequentar a escola, mas apenas 23.974 o faziam. Desse número, foi descontado um terço de crianças que recebiam instrução 
doméstica. Assim, conclui-se que de cada 60 crianças livres, apenas uma frequenta a aula pública, assim considerável número fica sem o "batismo da educação". ${ }^{20}$

Em outro registro, embora de educação da Corte (Rio de Janeiro), foi possível identificar conflitos interétnicos na preferência pelas aulas particulares ou pelo ensino em domicílio. José Ricardo Pires de Almeida (1989, p. 90), em obra escrita em fins do século XIX, registra:

as crianças das classes razoavelmente abastadas não vão a escola pública porque seus pais têm mais ou menos, o preconceito de cor ou porque temem, e com razão, pela moralidade de seus filhos, em contato com essa multidão de garotos cujos pais os enviam a escola apenas para se verem longe deles algumas horas. Deste modo, estas crianças aprendem melhor e mais depressa do que aqueles que freqüentam a escola pública.

Por outro lado, temos que a fiscalização em relação à frequência à instrução elementar recaía sobre a clientela das aulas públicas. $\mathrm{O}$ regulamento da lei de 1835 normalizou uma multa a ser paga pelos pais que não fizessem seus filhos frequentarem a aula pública, gerando inclusive listagens de "pais omissos". Esse procedimento deve-se a um conjunto de fatores e esteve relacionado à estruturação do ensino público. Para a existência de uma cadeira de instrução pública provida pelo professor e que justificasse gastos financeiros, era necessária a frequência de certo número de alunos, caso contrário, a cadeira era fechada. Por sua vez, a existência da instrução pública e do emprego público de professor eram fatores legitimadores de governo. Acresce-se ainda que os gestores políticos pretendiam exatamente o controle da educação das "camadas desfavorecidas".

$\mathrm{Na}$ pesquisa, foi possível detectar claramente que o grupo denominado desfavorecido pertencia à classe pobre, incluindo-se brancos pobres, além de negros e mestiços. Em geral, houve certa homogeneização no tratamento desse grupo como inferior com base em sua representação como grupo não-civilizado porque não afeito à lógica do mundo industrial, ou seja, como não-portadores de atitudes demandadas por uma nação que necessitava consolidar o progresso e constituir um público.

Nessa perspectiva, temos que a produção de dados estatísticos sobre a população apta a frequentar a escola não se fez pela cor das 
crianças, mas pela condição jurídica. Esse procedimento esteve de acordo também com a regulamentação da localização das escolas, ou seja, a criação de uma cadeira deveria ser efetiva em localidades que tivessem mais de 500 (1835) ou 600 (1866) habitantes livres. De acordo com a legislação, os juízes de paz deveriam encaminhar à presidência as listagens de crianças que atendiam aos quesitos de frequência à aula pública: crianças livres, sexo masculino, faixa etária de 8 a 14 anos (1835); de 8 a 15 (1872); de 7 a 12 anos (1879 $)^{21}$. A criação de aulas públicas para meninas era permitida e até estimulada, desde que as cadeiras fossem providas por professoras, mas somente em 1882 é que se instituiu para estas a frequência obrigatória.

A ausência do quesito cor na documentação investigada entre 1835 e 1889 sugere a existência de uma escola pluriétnica e corrobora os pressupostos das elites de civilizar a população "desfavorecida". Hebe Mattos (1998, p. 99), na discussão sobre tal ausência em processos-crimes, a partir da segunda metade do século XIX, afirma,

o crescente processo de indiferenciação entre brancos pobres e negros e mestiços livres teria levado, por motivos opostos a perda da cor de ambos. Não se trata necessariamente de branqueamento. Na maioria dos casos, tratase simplesmente de silêncio. $O$ sumiço da cor referencia-se, antes, a uma crescente absorção de negros e mestiços no mundo dos livres, que não é mais monopólio dos brancos...

No caso específico da institucionalização da obrigatoriedade escolar para a população livre, a ausência do quesito cor não se fez propriamente como silêncio, mas com o propósito aberto de educar as cores pela escola, pelo acesso à instrução.

A constatação do público-alvo ao qual se destinava a instrução pública elementar se fez por meio de registros distintos. No caso das referências à população pobre, ela é abundante e está presente nos relatórios de governo, ofícios e correspondências diversas, além de mapas de frequência que trazem observações sobre as crianças. Em se tratando da cor, somente foi possível a verificação por meio do cruzamento de dois tipos de documentação: os mapas da população livre (que possuíam o quesito cor) e as listas de meninos aptos a frequentar a aula pública (sem o quesito, por ser documento da instrução pública), ambos da mesma localidade e do mesmo ano. Podemos demonstrar, por exemplo, no "Mapa dos habitantes livres do 
arraial de Santo Antônio da Casa Branca e de um quarto de légua em roda"22, o fogo (grupo domiciliar) de número 66, sendo a chefe do fogo Ana Maria:

\begin{tabular}{|c|c|c|c|c|c|c|}
\hline $\mathrm{N}^{0}$ de $\mathrm{F}$ & habitantes & Nomes e idades & Estado & Qualidade & Ocupação* & Observações \\
\hline 66 & 338 & Ana Maria - 50 & Solteira & Crioula & & não sabe ler \\
\hline & 339 & Maria | Filhos - 20 & & & & \\
\hline & 340 & Thomásia - 16 & " & " & & " \\
\hline & 341 & Sabina -12 & ' & " & & " \\
\hline & 342 & Francisco - 07 & ". & " & & " \\
\hline & 343 & Antonio - 05 & ". & ". & & ". \\
\hline
\end{tabular}

* Não-registrado. Fonte: SP, Códice 233 (APM).

$\mathrm{Na}$ "Lista de meninos que há possibilidade de frequentarem huma Escola Pública de Instrução primária no Arraial de Casa Branca"23, estão listados os filhos, meninos, crioulos de Ana Maria:

\begin{tabular}{c|cc}
$\mathrm{N}^{0} \mathrm{~s}$ & Nomes e idades dos alunos & Pais ou educadores \\
\hline 95 & Francisco -07 & Ana Maria \\
96 & Antonio -05 &
\end{tabular}

Fonte: SP, Códice 233 (APM).

É importante reafirmar que somente foi possível identificar as cores das crianças devido ao fato de ter sido encontrado o mapa da população e que, na documentação estatística específica da instrução investigada o quesito cor não está presente. Ou seja, em princípio, a cor das crianças não se apresentou como problema de exclusão social. Inversamente, foi um problema de inclusão a ser resolvido pela escola.

\section{Escola indigente para uma população indigente?}

Nas fontes documentais investigadas, especialmente nos relatórios de governo, há imensa dissonância entre os discursos e as ações efetivas para se consolidar a instrução. De maneira geral, os relatórios são bem-escritos, apresentam dados estatísticos, assim como argumentações bem-fundamentadas sobre os problemas da precariedade do funcionamento das aulas da instrução. Ou melhor, foram textos elaborados por pessoas que possuíam informações a respeito dos acontecimentos relativos à difusão da educação nos países ditos civilizados. Apesar da 
existência de certa competência para se avaliar os problemas existentes na Província e inclusive indicar propostas de resolução em sintonia com os saberes em profusão na época, quase nada foi efetivado para que ocorressem mudanças.

Aventamos aqui algumas hipóteses que necessitariam estudos mais aprofundados. Os assuntos da educação eram fortemente centralizados na figura do presidente da Província, sendo que as medidas administrativas adotadas de criação de órgãos como Círculos Literários (1835), Diretoria Geral da Instrução Pública (1848) e a Inspetoria Geral da Instrução (1872) não favoreceram a autonomia para os ocupantes dos cargos. Por sua vez, a administração imperial foi caracterizada pela alta rotatividade na ocupação de cargos, seja de presidentes seja de outros, demonstrando a cultura política do império em sua perspectiva de clientelismo e favorecimentos. Portanto, os relatórios se apresentam como instrumentos de registro de fidelidade político-partidária, de cumprimento da lei, sendo que como, em parte, ela não é cumprida, ocorre o registro de suas justificativas. De um relato a outro há acúmulo de identificação de problemas, de justificativas, sem que ninguém os resolva. Estabelece-se, assim, a circulação de discursos políticos justificadores dos cargos que os gestores ocupam.

Outros problemas também podem ser considerados, como a vastidão do território, a precariedade ou a ausência de estradas, as dificuldades relativas à fiscalização do funcionamento das aulas. Certo é que, em 1881, um inspetor registra em seu relatório que a Província possuía apenas uma escola pública para 328 crianças, dessas, apenas 23 frequentavam as aulas, sendo que 21 nada aprendiam e, portanto apenas duas estavam "prontas" 24 . Em 1882, outro inspetor atestava que Minas Gerais possuía $75 \%$ de população analfabeta ${ }^{25}$.

Nas justificativas dos relatores, podemos organizar duas ordens de problemas. Uma primeira diz respeito aos professores e sua formação. Do ponto de vista da legislação, a regulamentação do magistério é a mais recorrente de todas as outras. Houve clara opção política em regulamentar o emprego público do professor em detrimento de sua formação. De um lado, proliferavam arranjos para a manutenção do cargo, disputas e querelas políticas locais; de outro, tem-se a enorme precariedade de funcionamento da escola normal. Além de seu funcionamento bastante irregular, até 1872, o currículo não ultrapassava o estudo de método de 
ensino e das disciplinas da instrução elementar. Em 1873, assim o inspetor relata:

Entre nós, geralmente falando, o menino matricula-se na escola na idade de cinco para seis anos e aos doze mal sabe soletrar e quando é feliz, assina com bastante desigualdade seu próprio nome. Seis anos de aprendizagem para tão mesquinho resultado forçosamente deve desanimar, principalmente a essa classe pobre, que vê no filho mais um recurso de que pode dispor para ajudalo a carregar o peso de uma vida, toda cheia de fadigas e necessidades. ${ }^{26}$

Embora os relatores sejam quase que unânimes em afirmar ser esse um dos principais problemas da instrução, mesmo com as alterações produzidas a partir da década de 70 , os dados continuam a revelar uma aprendizagem rotineira e limitada.

A outra ordem de questões refere-se às condições das crianças de frequentarem as aulas, estando nelas o estabelecimento de novas relações de autoridade, quais sejam o Estado e os responsáveis pelas crianças, os professores e os alunos.

O Estado estabeleceu a obrigatoriedade da frequência à aula elementar e os instrumentos de fiscalização da clientela-alvo da aula pública: a população mestiça e pobre. Essas regras geraram um conjunto documental que permite refletir sobre a precariedade material na qual essa população vivia. Assim, a pobreza das famílias é apresentada como elemento fundamental da infrequência ou da frequência irregular às aulas e, ao mesmo tempo, é fator que inviabilizava a cobrança das multas, ocorrendo, portanto, o não-cumprimento da lei. A pobreza é referida tanto pela falta de vestimentas para os meninos comparecerem à aula quanto pelo uso indiscriminado do trabalho infantil. No relato do presidente da Província de 1868, ele afirma:

a notável falta de freqüência que se tem dado nas escolas de instrução primária é conseqüência da pobreza, por que os pais empregando seus filhos nos serviços a que se consagram para poder alimentar-se e as suas famílias, não lhes sobrando recursos para sustenta-los e vesti-los nas povoações, deixam de manda-los a escola. ${ }^{27}$

Não somente quase todos os relatórios fazem referência à pobreza como também vários professores justificavam a ausência dos alunos devido a esse fator. É o caso da professora Raymunda Franco, que, tendo 
sido interrogada a respeito da frequência de seus alunos, encaminha correspondência ao inspetor em 18/3/1887 afirmando que: “... os pais não estão mandando os filhos para a escola por que os meninos tem que ir para a cidade vender leite..." ${ }^{28}$ Por vezes, a justificativa recai sobre os pais, que, por sua "ignorância", não compreendiam a importância da instrução, como podemos observar no relato do inspetor de 1867 :

já se vê, pois, que a instrução bebida nas escolas primárias quase que de nenhuma utilidade é na prática da vida, e talvez seja este o principal motivo que as classes inferiores de nossa sociedade olham com tanta indiferença para a educação literária que o estado gratuitamente lhes oferece e cujas vantagens práticas elas ainda não conseguiram descobrir. ${ }^{29}$

Além desses problemas, apresentam-se aqueles da constituição das relações entre as crianças e os professores. Esse fato é um acontecimento novo para grande parte da população, em especial para as crianças, tendo em vista que elas passariam a frequentar espaços e pessoas provavelmente estranhas ao seu convívio social, além de se submeterem a novos códigos identificadores, tais como a avaliação de seu desempenho e comportamento. Vimos que os alunos abandonavam as aulas devido ao trabalho e à pobreza, e ainda por não verem utilidade nos conhecimentos transmitidos, pelo procedimento rotineiro das aulas, mas também por situações de violência. Em diferentes registros, é possível detectar atitudes arbitrárias dos professores em relação aos alunos. Por exemplo, em correspondência de 5/4/1838 do delegado da instrução ao presidente da Província, aquele descreve o comportamento de um professor que desempenhava seus deveres do magistério, mas “...tem-se mostrado muito ríspido com os alunos, fazendo uso em demasia da palmatória...”. A firmase ainda que lhe ordenou que "os castigos não excedessem no máximo 5 palmatórias". ${ }^{30}$

\section{Considerações finais}

Gostaríamos de refletir sobre as práticas político-culturais de inclusão das crianças pobres e mestiças ao projeto de nação civilizada. É evidente a existência de forte tensão na implementação da lei de obrigatoriedade à frequência escolar, estabelecendo-se isso de forma 
coercitiva junto à população. Em ofício de 28/3/1836, assim um delegado expõe os motivos de uma mãe de família, Marta Ribeiro da Costa, parda, empregada numa fazenda de Contendas:

1. Mora a 6 léguas distante do Arraial, sede da aula, tem a seu cargo 2 filhas; sem outro meio de subsistência, além da lavoura, se emprega esta pobre família composta de 4 indivíduos, sendo o mais útil o filho, apesar da tenra idade. 2. Faltam todos os meios para manter aquele filho em qualquer aplicação. 3. Das razões alegadas, a suplicante pelo seu desvalimento não acha no Arraial quem o admita em casa e zele por sua pueris (...) de que é suscetível a natureza humana. Entregue o impúbere a descrição do tempo (...) as paixões, muito mais depressa se entregaria a corrupção e imoralidade que as lições ditadas pelo professor que de nada conhece fora da aula. 4. A suplicante se desencarregou da escola para aquele filho, "por causa de um só filho vem perder todos" (não tem como pagar a multa)... São estas as tristes circunstâncias da desgraçada. ${ }^{31}$

Essas situações de profundo constrangimento associam-se também às práticas de se elaborar as listas de "pais omissos". Temos, portanto, que a criação de uma situação de ilegalidade, de estar infringindo a lei, não foi acompanhada da criação de condições para as crianças terem frequência regular na escola e, principalmente, aprenderem o que se esperava delas, o saber elementar escolarizado. Os motivos, como vimos, foram de toda ordem, acrescentando-se ainda a total precariedade material da escola, com a ausência de material escolar, livros, bancos, além da falta de prédios escolares apropriados.

Ainda assim, os discursos dos gestores enfatizavam a educação popular como condição de progresso e civilização. No relatório de 1875, o vice-presidente da Província falava do empenho em generalizar a instrução de modo a "patentear a todo cidadão, ainda ao de mais humilde e obscura procedência" ${ }^{32}$. Entretanto, ao que tudo indica, os humildes e de obscura procedência não tiveram condições de permanência na instrução regular. Nesse sentido é que podemos concluir a respeito da existência de um código dual e contraditório presente nos processos de formação dos Estados-nação, como sugere Elias (1997), ou seja, o processo de institucionalização da instrução pública elementar se fez fundado em princípios universais e igualitários, como fator de integridade e coesão nacional. Dessa forma, estabeleceu-se como ação de inclusão social. Entretanto, as práticas político-culturais da inclusão se tornaram 
elas mesmas fatores de exclusão, na medida em que, por exemplo, a responsabilização por não mandarem as crianças à escola ou mesmo o "fracasso" das crianças que não aprendiam e abandonavam a aula do mestre recaía na relação dos indivíduos com o Estado. A escolarização, em seu sentido universal, se apresenta como fator preventivo da desordem, entretanto a condição anômica da população a torna responsável pela permanência de sua "ignorância". $\mathrm{Na}$ mesma lógica, elaborou-se a representação das crianças. Em relato de 1882, estando em pauta a questão das professoras assumirem turmas do sexo masculino, o inspetor faz as seguintes ressalvas,

... a índole de nossas crianças, máxime em vista da educação doméstica que recebem, a falta de limitação de idade para a freqüência das escolas confiadas a tal direção, e o fato de serem os alunos que a freqüentam de todas as procedências, o que é sem dúvida um elemento poderoso de desordem e perturbação da indispensável disciplina escolar, constituem embaraço sério a realização desse sistema de direção, capaz de frutificar proveitosamente só nas escolas freqüentadas por crianças escolhidas em vista da idade e dos precedentes de família.$^{33}$

Finalmente, queremos afirmar que em que pese a não-existência do impedimento legal de inclusão das crianças negras e mestiças nas escolas, os mecanismos internos de exclusão há muito estiveram presentes na história brasileira. Dessa maneira, ao ser anunciada a República (1889), já se tinha considerável acúmulo de conhecimentos a respeito desses processos, tornando necessária a depuração dos alunos de todas as procedências, a partir da elaboração de testes escolares e da instituição da escola graduada como práticas científicas de organização escolar. Para a escola deixar de ser indigente foi necessário que também sua clientela fosse outra, crianças de famílias de boa procedência.

\section{Referências}

BACZKO, Bronislaw. Imaginação social. Enciclopédia Einaudi: Antropos-Homem. Lisboa: Imprensa Nacional: Casa da Moeda, 1985.

BOTELHO, Ângela; ROMEIRO, Adriana. Dicionário Histórico das Minas Gerais. Belo Horizonte: Autêntica, 2003.

DUARTE, Regina Horta. Noites circenses. Espetáculos de circo e teatro em Minas Gerais no século XIX. Campinas, SP: Unicamp, 1995.

ELIAS, Norbert. O processo civilizador. Rio de Janeiro: Zahar, 1994. v. 1. 
ELIAS, Norbert. O processo civilizador.Rio de janeiro: Zahar, 1993. v. 2.

ELIAS, Norbert. Os alemães. Rio de Janeiro: Zahar, 1997.

ELIAS, Norbert; SCOTSON, John L. Os estabelecidos e os outsiders. Rio de Janeiro: Zahar, 2000.

FOUCAULT, Michel. A microfísica do poder. Rio de Janeiro: Graal, 1984.

GUIMARÃES, Antônio Sergio. Racismo e anti-racismo no Brasil. São Paulo: FEUSP, 1999.

GUTIERRÉZ, Horácio. Crioulos e africanos no Paraná, 1798-1830. Revista Brasileira de História, São Paulo, v. 8 n. 16, mar./ago. 1988.

KUHLMANN JR., Moysés. Infância e Educação infantil, uma abordagem bistórica. Porto Alegre: Mediação, 1998.

KUHLMANN JR., Moysés; FERNANDES, Rogério. Sobre a história da infância. In: FARIA FILHO (Org.) A Infância e sua educação. Belo Horizonte: Autêntica, 2004.

LARA, Silvia Hunold. Trabalhadores escravos. Trabalhadores. Campinas: Fundo de Assistência a Cultura, 1989.

LEITE, Ilka Boaventura. Antropologia da viagem. Belo Horizonte: UFMG, 1996.

LEITE, Miriam Moreira. A infância no século XIX segundo memórias e livros de viagem. In: FREITAS. (Org.) História social da infância no Brasil. São Paulo: Cortez, 1997. LENHARO, Alcir. As tropas da moderação. São Paulo: Símbolo, 1979.

LIBBY, Douglas. Transformação e trabalho em uma economia escravista: Minas Gerais no século XIX. São Paulo: Brasiliense, 1988.

MARTINS, Maria do Carmo Salazar. Revisitando a Província: comarcas, termos, distritos e população de Minas Gerais em 1833-35. V SEMINÁRIO SOBRE A ECONOMIA MINEIRA. Belo Horizonte: Cedeplar/ Face/UFMG, 1990.

MATTOS, Hebe de Castro. Laços de família e direitos no final da escravidão. In: ALENCASTRO (Org.) História da vida privada no Brasil. São Paulo: Companhia da Letras, 1997.

MATTOS, Hebe de Castro. Das cores do silêncio. Rio de Janeiro: Nova Fronteira, 1998.

PAULA, João Antônio de. Raízes da modernidade em Minas Gerais. Belo Horizonte: Autêntica, 2000.

REIS, Liana Maria. Poder, vadiagem e marginalização social em Minas Gerais. Revista de Ciências Históricas, Porto, 1995.

SOUZA, Laura de Mello e. Desclassificados do ouro. Rio de Janeiro: Graal, 1982.

VEIGA, Cynthia Greive. Infância e modernidade: ações, saberes e sujeitos. In: FARIA FILHO (Org.) A infância e sua educação. Belo Horizonte: Autêntica, 2004.

\section{Fontes documentais}

ALMEIDA, José Ricardo Pires de. História da Instrução Pública no Brasil (1500-1889). São Paulo: INEPE, (1889), 1989.

COLEÇÃO das Leis Mineiras, 1835-1890 (APM)

DANTAS JR., As constituições do Brasil. Bahia: Imprensa Oficial do Estado, 1937.

HALFELD, H. G. F.; TSCHUDI, J. J. von. A Provincia de Minas Gerais. Trad. Myriam Ávila, notas e revisão da tradução Roberto Martins. Belo Horizonte: Fundação João Pinheiro: Centro de Estudos Históricos e Culturais, 1998.

SILVA, José Bonifácio de Andrade e. Projetos para o Brasil. Organizado por Miriam 
Dolhnikoff. São Paulo: Companhia das Letras, 1998.

FALLA dirigida á Assembléa Legislativa Provincial na sessão ordinaria do anno de 1848 pelo presidente da província, Bernadino José de Queiroga. Ouro Preto, Typografia Social, 1848.

RELATORIO que o ilustríssimo e excelentíssimo senhor Doutor José Ricardo de Sá Rego, presidente desta Província, apresentou o Vice-Diretor da Instrução Pública, Chantre Antonio José Ribeiro Bhering em 1851. Ouro Preto, Typografia Social, 1852.

RELATORIO que sobre o estado da Instrução Pública e particular da Província de Minas Geraes apresentou o ilustríssimo e excelentíssimo senhor Doutor Luiz Antonio Barboza, muito digno Presidente da mesma província em 22 de fevereiro o vice-diretor geral, Chantre Antonio Jose Ribeiro Bhering. Ouro Preto, Typ. Do Bom Senso, 1852.

RELATORIO apresentado ao illmo.e exmo. Snr. Coronel Joaquim Camillo Teixeira da Motta, vice-presidente da província de Minas Geraes, pelo Inspetor da Meza das Rendas, Affonso Celso Assiz Figueiredo, em 16 de julho de 1862. Ouro Preto, Typ. De silva, 1862.

RELATORIO que á Assembléa Legislativa Provincial de Minas Geraes apresentou no acto da abertura da sessão ordinária de 1865 o dezembargador Pedro de Alcântara Cerqueira Leite, presidente da mesma província. Ouro Preto, Typ. Do Minas Gerais, 1865.

RELATORIO que apresentou ao exm. Sr, vice-presidente da Província de Minas Geraes Dr. Elias Pinto de Carvalho por ocasião de lhe passar a administração em 30 de junho de 1867 o conselheiro Joaquim Saldanha Marinho presidente da mesma província. Rio de Janeiro, Typografia Perseverança, 1867.

RELATORIO que á Assembléa Legislativa Provincial de Minas Geraes apresentou na sessão ordinária de 1868 o presidente da província, José da Costa Machado de Souza. Ouro Preto, Typ. De J. F. de Paula Castro, 1868.

RELATORIO com que o exm. Sr. Senador Joaquim Floriano de Godoy no dia 15 de janeiro de 1873 passou a administração da Província de Minas Geraes ao segundo vicepresidente Exm. Sr. Dr. Francisco Leite da Costa Belém por ocasião de retira-se para tomar assento na Câmara Vitalícia. Ouro Preto, 1873.

RELATORIO que ao Ilm. E Exm. Sr. Dr. Francisco Leite da Costa Belém, segundo vice-presidente da Província de Minas Geraes apresentou no ato de passar-lhe a administração da mesma província o exm. Sr. Desembargador João Antonio de Araújo Freitas Henriques, a 6 de março de 1875. Ouro Preto, Typ. De J. F. de Paula Castro, 1875. RELATORIO que á Assembléa Legislativa Provincial de Minas Geraes apresentou o exm. Sr. Senador João Florentino Meira de Vasconcellos, por ocasião de ser installada a mesma Assembléa para a segunda sessão ordinária de 23.a legislatura em 7 de agosto de 1881. Ouro Preto, Typ. Da Actualidade, 1881.

FALLA que o exm. Sr. Dr. Theophlo Ottoni dirigio á Assemblea Provincial de Minas Geraes, ao installar-se a 1.a sessão da 24.a legislatura em 1.o de agosto de 1882. Ouro Preto, Typ. De Carlos Andrade, 1882.

SEÇÃO Provincial, Instrução Pública 1/1, Caixa 58, Pacotilha 18 (Arquivo Público Mineiro).

SEÇÃO Provincial, Instrução Pública 1/3, Caixa 01, Pacotilha 17 (APM).

SEÇÃO Provincial, Instrução Pública 1/42, Caixa 05, Pacotilha 60 (APM). 
SEÇÃO Provincial, Instrução Pública 1/42, Caixa 10, Pacotilha 57 (APM).

SEÇÃO Provincial, Instrução Pública 3/2, Caixa 01, Pacotilha 05 (APM).

SEÇÃO Provincial, códice 233 (APM).

\section{Notas}

1 "História social da infância: crianças pobres, negras e mestiças no processo de institucionalização da instrução elementar em Minas Gerais (1835-1906)" integrada ao projeto de cooperação internacional Capes/Grices, "A infância e sua educação (18201950): materiais, práticas e representações" e a pesquisa desenvolvida no GEPHE/UFMG.

2 Botelho e Romeiro (2003). Capitania era uma divisão administrativa da qual se originaram, no Império, as províncias e, na República, os estados.

3 Esse movimento caracterizou-se por disputas políticas pelas questões relativas ao estabelecimento de Casas de Fundição (BOTELHO; ROMEIRO, 2003).

4 Entre outros, Lenharo (1979), Libby (1987) e Paula (2000).

5 Relatório, 1865, Anexo 8, p. 18.

6 Martins apud Halfeld e Tschudi (1998, p. 106).

7 Elias (2000, p. 32).

8 Nina Rodrigues (1862-1906) foi um dos pioneiros nos estudos raciais e usou como fonte relatos de viajantes como Debret, Martius e Spix (LEITE, 1996).

9 As constituições do Brasil (DANTAS JUNIOR, 1937).

10 Falla (1848, p. 26). Todos os relatórios foram consultados na base do Center for Research Libraries (http://www.crl.edu/content/brazil/mina.htm).

11 Andrada e Silva (1998, p. 170).

12 Relatório, 1865, apêndice 8, p. 41.

13 Relatório (1862, p. 18).

14 Chamo aqui atenção para as restrições encontradas na legislação do Rio de Janeiro e de São Pedro do Rio Grande do Sul. Na primeira, há a restrição para pretos africanos, mesmo que livres e libertos. É preciso considerar que preto africano não é brasileiro, sendo a denominação dos nascidos no Brasil crioulo (GUIMARÃES, 1999, p. 45). Na outra, é clara a restrição aos pretos (sem qualificação de africanos), o que merece ser mais bem-investigado, dada a sua inconstitucionalidade.

15 Apud Leite (1997, p. 38).

16 Sessão provincial (SP), Instrução Pública (IP) 3/2, Caixa (Cx.) 1, Pacotilha (P.) 17, Arquivo Público Mineiro (APM).

17 SP, IP 3/2, Cx. 01, p. 05, (APM).

18 Relatório (1852, p. 4).

19 Relatório (1852, p. 2).

20 Relatório, 1876, anexo 4, p. 94 
21 As idades estabelecidas em lei referem-se à obrigatoriedade, mas é possível encontrar meninos fora das faixas de idade fixadas arrolados como aptos a frequentar a escola ou registrados em mapas de frequência.

22 Sessão Provincial (SP), códice 233 (APM).

23 SP, códice 233 (APM).

24 Relatório, 1881, anexo 1, p. 52.

25 Relatório, 1882, anexo D, p. 8.

26 Relatório, 1873, anexo 21, p. 8.

27 Relatório (1868, p. 21).

28 SP, IP 1/1, Cx. 58, p. 18 (APM).

29 Relatório, 1867, anexo C, p. 2.

30 SP, IP 1/42, Cx. 10, p. 57 (APM).

31 SP, IP 1/42, Cx. 05, p. 60 (APM)

32 Não seria "superação do reducionismo da história dos negros à história da escravidão"?

Recebido: $27 / 10 / 2009$

Aprovado: 25/11/2009

Contato:

Universidade Federal de Minas Gerais

Faculdade de Educação

Departamento de Ciências Aplicadas a Educação

Av. Antonio Carlos 6627

Pampulha

CEP 31270-901

Belo Horizonte/MG 